\title{
Ảnh hưởng của thực tiễn quản trị nguồn nhân lực đến hiệu quả của hợp tác xã: Nghiên cứu trường họ̣p tại Thành phố Hồ Chí Minh
}

\section{External factors affect export performance of Vietnamese vegetable and fruit exporters}

\author{
Nguyễn Minh Hà ${ }^{*}$, Cấn Sơn Trường ${ }^{2}$, Nguyễn Thái Hải ${ }^{3}$ \\ ${ }^{1}$ Trường Đại học Mở Thành phố Hồ Chí Minh, Việt Nam \\ ${ }^{2}$ Sở Nông nghiệp và Phát triển Nông thôn Thành phố Hồ Chí Minh, Việt Nam \\ ${ }^{3}$ Trường Đại học Văn Lang, Việt Nam \\ *Tác giả liên hệ, Email: ha.nm@ou.edu.vn
}

THÔNG TIN

DOI: $10.46223 /$ HCMCOUJS. econ.vi.14.2.483.2019

Ngày nhận: 23/04/2019

Ngày nhận lại: 02/06/2019

Duyệt đăng: 20/06/2019

Tù khóa:

hiệu quả phi tài chính, hiệu quả tài chính, thực tiễn quản trị nguồn nhân lực

Keywords:

financial performance, human resource management practices, non-financial performance
TÓM TẮT

Nghiên cứu tìm hiểu các thành phần của thực tiễn quản trị nguồn nhân lực ảnh hưởng đến hiệu quả của hợp tác xã trên địa bàn Thành phố Hồ Chí Minh (TP.HCM). Nghiên cứu sử dụng phương pháp thống kê mô tả mẫu, phân tích độ tin cậy thang đo Cronbach's Alpha, phân tích nhân tố khám phá (EFA) và phân tích hồi quy đa biến. Dữ liệu được thu thập từ khảo sát 216 hợp tác xã trên địa bàn TP.HCM. Kết quả phân tích cho thấy 5 thành phần thực tiễn quản trị nguồn nhân lực (Tuyển dụng và lựa chọn lao động, đào tạo lao động, thị trường lao động nội bộ, sự tham gia của nhân viên và chế độ lương và đãi ngộ nhân viên) đều có tác động cùng chiều đến hiệu quả tài chính và hiệu quả phi tài chính của các hợp tác xã.

\section{ABSTRACT}

The study analyzes elements of human resource management practices influencing co-operatives' performance in Ho Chi Minh City. The study employs methods of descriptive statistics, analysis of Cronbach's Alpha, Exploratory Factor Analysis (EFA) and multiple regression using data collected from 216 co-operatives in Ho Chi Minh City. The findings show that all five elements of human resource management practices (recruitment and labour selection, training, internal labour market, employee's engagement, and compensation and benefits policy) have a positive correlation with co-operatives' financial and non-financial performance. 


\section{Giới thiệu}

Theo Luật ở Việt Nam, theo Luật Hợp tác xã, số 23 (Quốc Hội, 2012), "Hợp tác xã (HTX) là tổ chức kinh tế tập thể, đồng sở hữu, có tu cách pháp nhân, do it nhất 07 thành viên tụ nguyện thành lập và hợp tác tuoong trọ lẫn nhau trong hoạt động sản xuất, kinh doanh, tạo việc làm nhằm đáp ứng nhu cầu chung của thành viên, trên cơ sở tụ chủ, tụ chịu trách nhiệm, bình đẳng và dân chủ trong quản lý HTX'. HTX là trào lưu có tổ chức lớn nhất của xã hội văn minh, đóng vai trò quan trọng trong việc đáp ứng nguyện vọng, nhu cầu của con người trong nỗ lực phát triển cân bằng và sâu rộng từng quốc gia nói riêng và trên thế giới nói chung (United Nations, 2003). Trong lĩnh vực nông nghiệp, HTX là 1 tổ chức có lợi thế trong việc giảm chi phí sản xuất và phù hợp với nền sản xuất nông nghiệp (Valentinov, 2007) nên HTX giúp nông nghiệp phát triển kéo theo sự phát triển chung của vùng nông thôn (Aref, 2011). Trong lĩnh vực thương mại, dịch vụ, các HTX đã góp phần phục vụ sản xuất, bình ổn giá cả thị trường, giải quyết việc làm và tăng thu nhập cho người lao động (Ban Kinh tế Trung ương, 2015). Như vậy, vai trò của $\mathrm{HTX}$ đã được khẳng định là tác nhân quan trọng trong việc phát triển kinh tế, xã hội của các nước trên thế giới, trong đó có Việt Nam (Wolz \& Pham, 2010).

Có thể nói rằng nhân lực là nguồn lực quan trọng nhất và là tài sản quý giá cho sự phát triển và tồn tại của các HTX. Cũng như các tổ chức khác đang trong môi trường cạnh tranh thường xuyên và đòi hỏi không ngừng nâng cao hiệu quả (Harel \& Tzafrir, 1999), HTX của TP.HCM phải tìm cách nâng cao hiệu quả hoạt động để tồn tại, phát triển. Bên cạnh đó, một số nghiên cứu đã chỉ ra rằng hiệu quả tổ chức (Organizational Performance) có sự liên quan mật thiết với việc ứng dụng thực tiễn quản trị nguồn nhân lực (QTNNL) trong tổ chức đó, cụ thể thực tiễn QTNNL có tác động tích cực đến sự thành công của tổ chức, doanh nghiệp (Becker \& Gerhart, 1996; Rogers \& Wright, 1998). Như vậy, nếu các HTX của TP.HCM ứng dụng tốt thực tiễn QTNNL vào hoạt động sẽ mang lại hiệu quả cho HTX. Bên cạnh đó, ảnh hưởng của thực tiễn QTNNL được nghiên cứu ở nhiều ngành nghề và nhiều khía cạnh khác nhau nhưng chưa có nghiên cứu chính thức về hiệu quả tổ chức trong khu vực kinh tế tập thể ở nước ta, đặc biệt là các HTX.

\section{Cơ sở lý thuyết và giả thuyết nghiên cứu}

Quản trị nguồn nhân lực là việc thiết kế các hệ thống chính thức trong một tổ chức để đảm bảo hiệu quả và hiệu quả sử dụng tài năng của con người nhằm thực hiện các mục tiêu của tổ chức (Mathis \& Jackson, 2010). Quản trị nhân lực nhằm mục đích tuyển chọn được những người có năng lực, nhanh nhạy và cống hiến trong công việc, quản lý hoạt động và khen thưởng kết quả hoạt động cũng như phát triển năng lực của họ (Price, 2007). Theo Armstrong (2006), thực tiễn QTNNL là một cách tiếp cận mang tính chiến lược và chặt chẽ để quản lý tài sản có giá trị nhất của 1 tổ chức - đó là những con người đang làm việc và đóng góp cho tổ chức nhằm đạt được các mục tiêu đề ra của tổ chức đó. Như vậy, có thể nói rằng thực tiễn QTNNL là các hoạt động quản lý nguồn nhân lực của tổ chức để hoàn thành các mục tiêu của tổ chức đó. 
Hiệu quả tài chính của tổ chức: Hiệu quả về tài chính được đo lường sự thành công về tài chính của tổ chức bao gồm tỷ suất sinh lợi trên tổng tài sản, tỷ suất sinh lợi trên vốn chủ sở hữu (Le, 2013); tỷ suất sinh lợi trên vốn đầu tư, tỷ suất sinh lợi trên doanh thu, tăng trưởng tỷ suất sinh lợi trên vốn đầu tư, tăng trưởng doanh thu (Li, Ragu-Nathan, Ragu-Nathan, \& Rao, 2006). Đã có nhiều nghiên cứu đo lường hiệu quả tài chính của tổ chức bằng cảm nhận đối với các chỉ tiêu của tổ chức như: lợi nhuận hàng năm, tăng trưởng lợi nhuận, tăng trưởng doanh thu, giá trị gia tăng hay doanh số trên mỗi nhân viên (Cappelli \& Neumark, 2001; Delaney \& Huselid, 1996; Le, 2013; Terpstra \& Rozell, 1993) để đo lường hiệu quả về tài chính của tổ chức đó. Rhee, Zhao, và Kim (2014) cũng cho rằng hiệu quả tài chính của doanh nghiệp có thể đo lường bằng cảm nhận về doanh thu, lợi nhuận, năng suất, thị phần.

Hiệu quả phi tài chính của tổ chức: Li và cộng sự (2006) cho rằng hiệu quả thị trường bao gồm thị phần, tăng trưởng về thị phần. Hiệu quả phi tài chính có 2 thành phần là lợi thế cạnh tranh và hiệu quả về chiêu thị (Le, 2013). Lợi thế cạnh tranh bao gồm chất lượng sản phẩm/dịch vụ; sự phát triển sản phẩm mới, khả năng thu hút nhân viên của tổ chức; khả năng giữ chân nhân viên, sự hài lòng của khách hàng/đối tác; mối quan hệ giữa quản lý và nhân viên. Hiệu quả về thị trường bao gồm chia sẻ thị trường, khả năng đứng vững trên thị trường, cổ tức tăng trên thị trường chứng khoán. Delaney và Huselid (1996) lập luận cảm nhận về hiệu quả phi tài chính tập trung ở các khía cạnh về chiêu thị. Rhee và cộng sự (2014) đo lường hiệu quả phi tài chính đối với chất lượng, sự cạnh tranh về giá, tiết kiệm chi phí sản phẩm, phát triển sản phẩm mới, sự hài lòng của khách hàng, sự quan tâm về sở hữu trí tuệ của doanh nghiệp.

Các thành phần của thực tiễn QTNNL có tác động đến hiệu quả tổ chức: Có nhiều nghiên cứu trước đưa ra các thành phần của thực tiễn QTNNL có tác động đến hiệu quả tổ chức. Trong đó, các thành phần của thực tiễn QTNNL có ảnh hưởng đến hiệu quả tổ chức gồm 5 thành phần: (1) tuyển dụng và lựa chọn lao động, (2) đào tạo, $(3)$ thị trường lao động nội bộ, (4) sự tham gia của nhân viên và (5) chế độ lương và đãi ngộ, cụ thể:

Tuyển dụng và lụa chọn lao động đối với hiệu quả tổ chức: Theo Bratton và Gold (2001) as cited by Ofori và Aryeetey (2011), tuyển dụng (recruitment) là quá trình tạo ra một nguồn lao động có khả năng đáp ứng yêu cầu làm việc của một tổ chức và lựa chọn (selection) là quá trình mà các nhà quản lý và những người khác sử dụng các công cụ chuyên dùng để lựa chọn từ nguồn các ứng viên nêu trên chọn ra một số người có nhiều khả năng để thành công trong công việc nhất phù hợp với mục tiêu quản lý và yêu cầu pháp lý của tổ chức đó. Tuyển dụng và lựa chọn là một trong những thành phần của thực tiễn QTNNL được áp dụng để làm tăng kỹ năng của nhân viên. Nhân viên có thể được thuê thông qua các quy trình lựa chọn được thiết kế một cách tinh tế để lọc ra tất cả trừ những nhân viên có tiềm năng tốt nhất (Delaney \& Huselid, 1996). Thật vậy, một số nghiên cứu cho thấy tuyển dụng và lựa chọn nhân viên có tác động tích cực đến hiệu quả tổ chức (Becker \& Huselid, 1992; Schmidt, Hunter, McKenzie, \& Muldrow, 1979 as cited by Delaney \& Huselid, 1996; Ekwoaba, Ikeije, \& Ufoma, 2015). Dựa vào lập luận trên, giả thuyết được đặt ra:

H1.a: Tuyển dụng và lụa chọn lao động càng hiệu quả thì hiệu quả tài chính càng cao 
H1.b: Tuyển dụng và lụa chọn lao động càng hiệu quả thì hiệu quả phi tài chính càng cao

Đào tạo lao động đối với hiệu quả tổ chức: Đào tạo là việc sử dụng các hoạt động giảng dạy có hệ thống và có kế hoạch để thúc đẩy học tập (Armstrong \& Taylor, 2014). Theo Delaney và Huselid (1996), đào tạo là thành phần thực tiễn QTNNL thứ hai (sau tuyển dụng và lựa chọn) có thể làm tăng kỹ năng của nhân viên. Tổ chức có thể nâng cao chất lượng nhân viên hiện tại bằng cách cung cấp các hoạt động đào tạo và phát triển toàn diện sau khi đã lựa chọn nhân viên. Nhiều bằng chứng đáng tin cho thấy rằng đầu tư vào đào tạo mang lại kết quả có lợi và hiệu quả cho tổ chức (Bartel, 1994; Combs, Liu, Hall, \& Ketchen, 2006; Delaney \& Huselid, 1996; Huang, 2001). Dễ dàng thấy rằng nhân viên có trang bị kĩ năng và kiến thức tốt sẽ giúp tăng cường năng suất sản xuất, cải tiến chất lượng của hàng hóa và dịch vụ, mang lại quá trình thay đổi tích cực và hiện thực hóa việc phân phối chất lượng các dịch vụ đến khách hàng. Nói theo cách khác, chúng giúp tăng cường hiệu quả và sự cạnh tranh trong tổ chức (Yazam \& Ahmid, 2011 as cited by Rhee et al., 2014). Do đó, giả thuyết được đặt ra:

H2.a: Đào tạo lao động càng được đầu tu nhiều thì hiệu quả tài chính càng cao

H2.b: Đào tạo lao động càng được đầu tư nhiều thì hiệu quả phi tài chính càng cao

Thị trương lao động nội bộ đối với hiệu quả tổ chức: Theo Harel và Tzafrir (1999), thị trường lao động nội bộ (internal labor market) được hiểu là sự luân chuyển, điều động nhân viên theo chiều dọc hoặc chiều ngang trong nội bộ của tổ chức, tức là bổ nhiệm nhân viên lên 1 cấp cao hơn hoặc điều động từ bộ phận này sang bộ phận khác. Còn Dorringer và Piore (1985) định nghĩa thị trường lao động nội bộ là một tổ chức hành chính, trong đó có các quy định và nguyên tắc về đãi ngộ người lao động và phân bổ nguồn nhân lực cho tổ chức. Thị trường lao động nội bộ tạo ra cơ hội cho nhân viên thăng tiến trong tổ chức của mình (Delaney \& Huselid, 1996). Tính di động của nhân viên trong tổ chức, theo chiều ngang và theo chiều dọc, có thể cải thiện hiệu quả tổ chức theo hai cách: trực tiếp, thông qua kiến thức, kinh nghiệm và sự hài lòng; và gián tiếp, bằng cách giảm tuyển dụng, lựa chọn và chi phí đào tạo (Milkovich \& Boudreau, 1994 as cited by Harel \& Tzafrir, 1999). Nghiên cứu của Makovskay (2008) nhấn mạnh thị trường lao động nội bộ đem lại lợi ích cho cả tổ chức và người lao động. Khi sử dụng nguồn nhân lực từ thị trường lao động nội bộ, tổ chức sẽ tiết kiệm được chi phí tuyển dụng, giảm thiểu rủi ro khi có nhân viên nghỉ việc, tiết kiệm chi phí phải đào tạo lại nhân viên mới, chi phí thỏa thuận với nhân viên mới, thụ hưởng được thành quả từ việc đầu tư đào tạo lao động tại chỗ. Nhân viên được đảm bảo việc làm và thu nhập, có khả năng thăng tiến, tiết kiệm thời gian và chi phí nếu phải tìm việc làm bên ngoài, được đảm bảo phúc lợi xã hội. Việc tổ chức trao cơ hội thăng tiến cho nhân viên của mình cũng được một số tác giả tìm ra có ảnh hưởng tích cực đến hiệu quả tổ chức và tăng động lực cho nhân viên (Delaney \& Huselid, 1996; Harel \& Tzafrir, 1999; Rhee et al., 2014). Như vậy, giả thuyết được đưa ra:

H3. a: Nhân viên được trao co hội thăng tiến thông qua thị truờng lao động nội bộ càng nhiều thì hiệu quả tài chính càng cao 
H3.b: Nhân viên được trao co hội thăng tiến thông qua thị truờng lao động nội bộ càng nhiều thì hiệu quả phi tài chính càng cao

Sụ tham gia của nhân viên đối với hiệu quả tổ chức: Strauss (2006) cho rằng sự tham gia là một quá trình cho phép nhân viên kiểm soát công việc của họ và những điều kiện mà họ làm việc. Sự tham gia còn là mức độ ảnh hưởng mà một cá nhân tác động đến quá trình ra quyết định của tổ chức và các vấn đề đa dạng được thảo luận có liên quan đến những quyết định được đưa ra (Verma, 1995 as cited by Harel \& Tzafrir, 1999). Theo Marchington, Wilkinson, Ackers, và Dundon (2001), sự tham gia của nhân viên có 2 loại: (1) sự tham gia trực tiếp trong việc yêu cầu giải quyết các vấn đề cá nhân hoặc xây dựng nhóm, (2) sự tham gia gián tiếp thông qua các tổ chức đại diện nơi làm việc. Bratton và Gold (2001) cho rằng các công ty muốn đạt được lợi thế cạnh tranh bền vững thì nên giúp nhân viên của họ chủ động tham gia vào các quá trình ra quyết định và các vấn đề hàng ngày của tổ chức. Nhiều nghiên cứu đã nhận thấy rằng việc tham gia của nhân viên có ảnh hưởng tích cực đến hiệu quả tổ chức, đồng thời làm gia tăng sự thỏa mãn của nhân viên cũng như năng suất làm việc của họ. Sự tham gia tích cực của nhân viên có thể ảnh hưởng đến hiệu quả tổ chức, giải quyết các vấn đề cá nhân, tăng cường tính tự chủ cho các đội nhóm, qua đó, làm tăng quyền tự chủ và sự hài lòng của nhân viên (Batt, 2002). Vì vậy, giả thuyết đặt ra:

H4.a: Sụ tham gia của nhân viên càng nhiều thì hiệu quả tài chính càng cao

H4.b: Sụ tham gia của nhân viên càng nhiều thì hiệu quả phi tài chính càng cao

Chế độ lương và đãi ngộ cho nhân viên đối với hiệu quả tổ chức: Để giữ vững năng lực cạnh tranh, các công ty phải phát triển các gói khen thưởng để thỏa mãn người lao động (Mathis \& Jackson, 2010). Các tổ chức có thể áp dụng hệ thống trả lương hoặc chế độ đãi ngộ khen thưởng cho nhân viên để đáp ứng các mục tiêu cụ thể (Delaney \& Huselid, 1996). Theo Mathis và Jackson (2010), chế độ đãi ngộ có 3 loại: tiền lương cơ bản (base pay), tiền thưởng (variable pay), phúc lợi (benefit). Một khối lượng lớn bằng chứng đã tập trung vào tác động của hệ thống chế độ khen thưởng và hệ thống quản lý hiệu quả đến hiệu quả tổ chức (Gerhart \& Milkovich, 1992 as cited by Delaney \& Huselid, 1996). Trong thực tế, sự đãi ngộ và khen thưởng sẽ đưa đến động lực làm việc, sự cam kết, sự hài lòng của nhân viên (Katou, 2008; ALDamoe \& ctg, 2011 as cited by Rhee et al., 2014) và thậm chí có thể ảnh hưởng đến năng suất sản xuất, bán hàng, và hiệu quả tổ chức tổng thể (Delaney \& Huselid, 1996; Rhee et al., 2014). Vì vậy, có những bằng chứng rõ ràng rằng sự đãi ngộ và khen thưởng có ảnh hưởng đáng kể đến hiệu quả tổ chức. Từ đó, giả thuyết được đưa ra:

H5.a: Chế độ luơng và đãi ngộ cho nhân viên càng nhiều thì hiệu quả tài chính càng cao

H5.b: Chế độ luơng và đãi ngộ cho nhân viên càng nhiều thì hiệu quả phi tài chính càng cao 


\section{Phương pháp nghiên cứu và dữ liệu nghiên cứu}

\subsection{Mô hình nghiên cúu}

Từ cơ sở lý thuyết về mối quan hệ giữa thực tiễn QTNNL với hiệu quả tổ chức và các nghiên cứu trước đây, nghiên cứu dựa trên cơ sở mô hình của Rhee và cộng sự (2014), Harel và Tzafir (1999) đề xuất như sau:

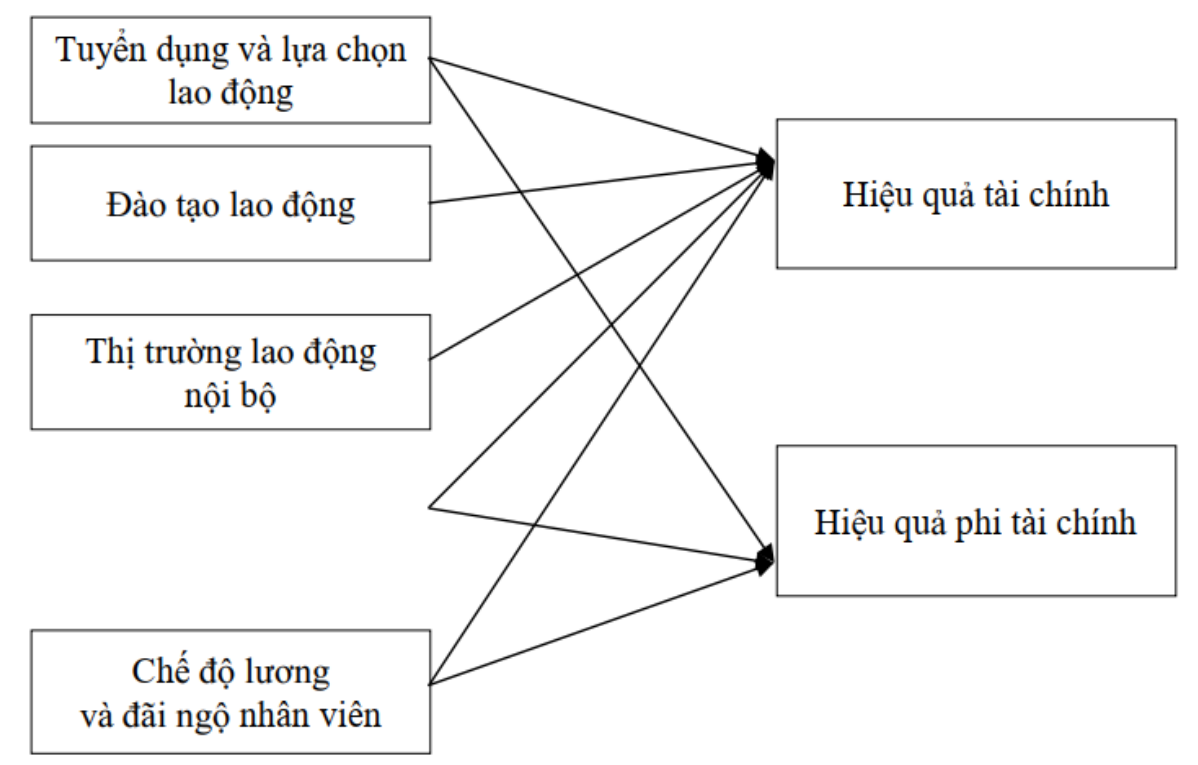

Hình 1. Mô hình hệ thống khí canh đã thiết kế

\subsection{Phwơng pháp nghiên cúu}

Nghiên cứu sử dụng phương pháp nghiên cứu định tính, nghiên cứu định lượng, sử dụng các kỹ thuật phân tích: phương pháp thống kê mô tả mẫu, phân tích độ tin cậy thang đo Cronbach's Alpha, phân tích nhân tố khám phá EFA, và phân tích hồi quy đa biến. Thang đo của các biến độc lập và biến phụ thuộc được thiết kế theo Likert 5 (từ mức độ 1 là: Hoàn toàn không đồng ý đến mức độ 5 là: Hoàn toàn đồng ý). Thang đo cho các thành phần thực tiễn QTNNL gồm 05 yếu tố với 28 biến quan sát và Thang đo cho biến hiệu quả tổ chức gồm 02 yếu tố với 14 biến quan sát (trong Bảng 2).

\subsection{Dũ liệu nghiên cúuu}

Đối tượng khảo sát nghiên cứu là Lãnh đạo của các hợp tác xã (Chủ tịch Hội đồng quản trị/Giám đốc/Phó Giám đốc) trên địa bàn TP.HCM. Lấy mẫu theo phương pháp chọn mẫu thuận tiện phi xác suất. Tổng số phiếu khảo sát phát ra là 300 thông qua hình thức phát bảng câu hỏi trực tiếp - thu về và thông qua email gởi trực tiếp, thu về 242. Sau khi lọc, loại 26 phiếu còn 216 phiếu khảo sát đưa vào phân tích chính thức, đạt tỉ lệ 89,3\% so với thu về.

\section{Kết quả nghiên cứu}

\subsection{Thống kê mô tả mẫu}

Kết quả thống kê mẫu được thể hiện trong Bảng 1 như sau: 


\section{Bảng 1}

Thống kê mô tả đặc điểm của mẫu khảo sát

\begin{tabular}{|c|l|c|c|}
\hline \multicolumn{2}{|c|}{ Thông tin HTX được khảo sát } & Tần số & Tần suất (\%) \\
\hline \multirow{3}{*}{$\begin{array}{c}\text { Lĩnh vực } \\
\text { hoạt động }\end{array}$} & Nông nghiệp, dịch vụ nông nghiệp & 35 & 16,2 \\
\cline { 2 - 4 } & Thương mại, dịch vụ & 103 & 47,7 \\
\cline { 2 - 4 } & Công nghiệp, tiểu thủ công nghiệp & 47 & 21,8 \\
\cline { 2 - 4 } & Khác & 31 & 14,4 \\
\hline \multirow{3}{*}{$\begin{array}{c}\text { Số năm } \\
\text { hoạt động }\end{array}$} & Dưới 2 năm & 55 & 25,5 \\
\cline { 2 - 4 } & Từ 2 đến 5 năm & 102 & 47,2 \\
\cline { 2 - 4 } & Từ 6 đến 10 năm & 43 & 19,9 \\
\cline { 2 - 4 } & Trên 10 năm & 16 & 7,4 \\
\hline \multirow{3}{*}{$\begin{array}{c}\text { Số lượng } \\
\text { lao động }\end{array}$} & Từ 1 đến 10 lao động & 92 & 42,6 \\
\cline { 2 - 4 } & Từ 11 đến 30 lao động & 99 & 45,8 \\
\cline { 2 - 4 } & Từ 31 đến 50 lao động & 7 & 8,3 \\
\cline { 2 - 4 } & Trên 50 lao động & 3,2 \\
\hline
\end{tabular}

Nguồn: Kết quả phân tích dữ liệu của nhóm nghiên cứu

Về lĩnh vực hoạt động: Kết quả khảo sát cho thấy nhóm HTX hoạt động trong lĩnh vực thương mại, dịch vụ chiếm tỷ lệ cao nhất là 47,7\%, kế đến là nhóm HTX hoạt động trong lĩnh vực công nghiệp, tiểu thủ công nghiệp với $21,8 \%$, nhóm HTX hoạt động trong lĩnh vực nông nghiệp, dịch vụ nông nghiệp là $16,2 \%$ và cuối cùng là nhóm HTX hoạt động trong lĩnh vực khác là $14,4 \%$.

Về thời gian hoạt động: Nhóm HTX có thời gian hoạt động từ 2-5 năm chiếm tỷ lệ cao nhất (47,2\%), kế đến là nhóm HTX có thời gian hoạt động dưới 2 năm $(25,5 \%)$, nhóm HTX có thời gian hoạt động từ 6-10 năm $(19,9 \%)$ và nhóm HTX có thời gian hoạt động trên 10 năm chiếm ít nhất $(7,4 \%)$.

Về số lượng lao động: Theo kết quả khảo sát cho thấy nhóm HTX có từ 11 đến 30 lao động chiếm tỷ lệ cao nhất $(45,8 \%)$, kế đến là nhóm HTX có từ 1 đến 10 lao động $(42,6 \%)$, nhóm HTX có từ 31 đến 50 lao động $(8,3 \%)$, cuối cùng là nhóm HTX có trên 50 lao động $(3,2 \%)$.

\subsection{Thống kê các biến quan sát trong mô hình}

\section{Bảng 2}

Thống kê mô tả các biến quan sát

\begin{tabular}{|c|c|c|c|c|c|c|}
\hline Mã hóa & Biến quan sát & $\mathbf{N}$ & $\begin{array}{l}\text { Nhỏ } \\
\text { nhất }\end{array}$ & $\begin{array}{l}\text { Lớn } \\
\text { nhất }\end{array}$ & $\begin{array}{l}\text { Trung } \\
\text { bình }\end{array}$ & $\begin{array}{l}\text { Độ lệch } \\
\text { chuẩn }\end{array}$ \\
\hline \multicolumn{7}{|c|}{ Thang đo: Tuyển dụng và lựa chọn lao động } \\
\hline TD1 & $\begin{array}{l}\text { HTX có thực hiện nhiều chương trình tuyê̂̉ dụng khác } \\
\text { nhau để thu hút những nhân viên có năng lực. }\end{array}$ & 216 & 2 & 5 & 3,30 &, 713 \\
\hline TD2 & $\begin{array}{l}\text { HTX có xây dựng tiêu chí cụ thể về kỹ năng và năng } \\
\text { lực cần thiết mà nhân viên mới phải có. }\end{array}$ & 216 & 2 & 5 & 3,75 & 692 \\
\hline
\end{tabular}




\begin{tabular}{|c|c|c|c|c|c|c|}
\hline Mã hóa & Biến quan sát & $\mathbf{N}$ & $\begin{array}{l}\text { Nhỏ } \\
\text { nhất }\end{array}$ & $\begin{array}{l}\text { Lớn } \\
\text { nhất }\end{array}$ & \begin{tabular}{c|} 
Trung \\
bình
\end{tabular} & $\begin{array}{c}\text { Độ lệch } \\
\text { chuẩn }\end{array}$ \\
\hline TD3 & $\begin{array}{l}\text { HTX có quan tâm đến trình độ chuyên môn của nhân } \\
\text { viên. }\end{array}$ & 216 & 2 & 5 & 3,25 & ,710 \\
\hline TD4 & $\begin{array}{l}\text { Quá trình tuyển dụng nhân sự mới của HTX diễn ra } \\
\text { công bằng. }\end{array}$ & 216 & 2 & 5 & 3,70 &, 725 \\
\hline TD5 & $\begin{array}{l}\text { Thông tin tuyển dụng nhân sự của HTX được công } \\
\text { khai. }\end{array}$ & 216 & 2 & 5 & 3,15 &, 739 \\
\hline TD6 & $\begin{array}{l}\text { Cán bộ chủ chốt của HTX có tham gia vào quá trình } \\
\text { tuyển dụng nhân sự mới. }\end{array}$ & 216 & 2 & 5 & 3,39 &, 727 \\
\hline \multicolumn{7}{|c|}{ Thang đo: Đào tạo lao động } \\
\hline DT1 & $\begin{array}{l}\text { HTX có thường xuyên khảo sát về nhu cầu nâng cao } \\
\text { trình độ của nhân viên. }\end{array}$ & 216 & 2 & 5 & 3,56 & ,699 \\
\hline DT2 & $\begin{array}{l}\text { HTX có đào tạo cho nhiều đối tượng nhân viên trong } \\
\text { HTX như: nhân viên kinh doanh, nhân viên kỹ thuật, } \\
\text { nhân viên hành chính-kế toán,... }\end{array}$ & 216 & 1 & 5 & 3,22 & ,743 \\
\hline DT3 & $\begin{array}{l}\text { HTX có thường xuyên lập kế hoạch đào tạo cho nhân } \\
\text { viên. }\end{array}$ & 216 & 2 & 5 & 3,44 &, 739 \\
\hline DT4 & HTX có đào tạo theo nhu cầu của nhân viên. & 216 & 2 & 5 & 3,13 & 679 \\
\hline DT5 & $\begin{array}{l}\text { HTX có đánh giá kết quả đào tạo sau khi nhân viên } \\
\text { hoàn thành khóa đào tạo. }\end{array}$ & 216 & 1 & 5 & 3,15 &, 775 \\
\hline DT6 & $\begin{array}{l}\text { HTX có đào tạo nhân viên theo định hướng phát triển } \\
\text { của HTX. }\end{array}$ & 216 & 2 & 5 & 3,20 & ,704 \\
\hline \multicolumn{7}{|c|}{ Thang đo: Thị trường lao động nội bộ } \\
\hline TT1 & $\begin{array}{l}\text { Nhân viên được quy hoạch trở thành đội ngũ kế thừa } \\
\text { vào vị trí điều hành của HTX. }\end{array}$ & 216 & 2 & 5 & 3,09 & ,796 \\
\hline TT2 & $\begin{array}{l}\text { Nhân viên được tạo cơ hội để luân chuyển, phát triển } \\
\text { ở các vị trí, bộ phận khác nhau trong HTX. }\end{array}$ & 216 & 2 & 5 & 3,25 &, 717 \\
\hline TT3 & $\begin{array}{l}\text { Nhân viên được tạo cơ hội bổ nhiệm vào vị trí điều } \\
\text { hành HTX. }\end{array}$ & 216 & 2 & 5 & 3,30 &, 763 \\
\hline TT4 & $\begin{array}{l}\text { Cơ hội thăng tiến được thực hiện một cách công bằng } \\
\text { cho tất cả nhân viên. }\end{array}$ & 216 & 2 & 5 & 3,13 &, 761 \\
\hline TT5 & Việc bổ nhiệm nhân sự mới được thực hiện công khai. & 216 & 2 & 5 & 3,05 & ,736 \\
\hline \multicolumn{7}{|c|}{ Thang đo: Sự tham gia của nhân viên } \\
\hline TG1 & $\begin{array}{l}\text { Lãnh đạo HTX có tham khảo ý kiến của nhân viên } \\
\text { trong quá trình ra quết định. }\end{array}$ & 216 & 2 & 5 & 3,14 & ,604 \\
\hline TG2 & $\begin{array}{l}\text { Lãnh đạo HTX có yêu cầu các Trưởng bộ phận của } \\
\text { HTX tham khảo ý kiến của nhân viên trong quá trình } \\
\text { ra quyết định. }\end{array}$ & 216 & 2 & 5 & 3,62 &, 558 \\
\hline TG3 & $\begin{array}{l}\text { Lãnh đạo HTX tạo điều kiện cho nhân viên đề xuất cải } \\
\text { tiến hoạt động của HTX. }\end{array}$ & 216 & 1 & 5 & 3,67 &, 747 \\
\hline TG4 & $\begin{array}{l}\text { Lãnh đạo HTX có giao tiếp với nhân viên một cách } \\
\text { niềm nờ. }\end{array}$ & 216 & 2 & 5 & 3,24 &, 558 \\
\hline
\end{tabular}




\begin{tabular}{|c|c|c|c|c|c|c|}
\hline Mã hóa & Biến quan sát & $\mathbf{N}$ & $\begin{array}{l}\text { Nhỏ } \\
\text { nhất }\end{array}$ & $\begin{array}{l}\text { Lớn } \\
\text { nhất }\end{array}$ & $\begin{array}{c}\text { Trung } \\
\text { bình }\end{array}$ & $\begin{array}{l}\text { Độ lệch } \\
\text { chuẩn }\end{array}$ \\
\hline TG5 & $\begin{array}{l}\text { Nhân viên có nhiều cơ hội thảo luận và tham gia vào } \\
\text { việc xây dựng chương trình, kế hoạch của HTX. }\end{array}$ & 216 & 2 & 5 & 3,11 &, 531 \\
\hline TG6 & $\begin{array}{l}\text { Nhân viên có thể đề đạt các nguyện vọng về cải tiến, } \\
\text { đồi mới công việc tại HTX. }\end{array}$ & 216 & 2 & 5 & 3,07 &, 715 \\
\hline \multicolumn{7}{|c|}{ Thang đo: Chế độ lương và đãi ngộ } \\
\hline DN1 & $\begin{array}{l}\text { Chế độ lương và đãi ngộ của HTX phản ánh đúng tính } \\
\text { chất công việc. }\end{array}$ & 216 & 2 & 5 & 3,77 & ,632 \\
\hline DN2 & $\begin{array}{l}\text { Chế độ lương và đãi ngộ của HTX phản ánh đúng yêu } \\
\text { cầu công việc của mỗi nhân viên. }\end{array}$ & 216 & 2 & 5 & 3,28 &, 578 \\
\hline DN3 & $\begin{array}{l}\text { Chế độ lương và đãi ngộ của HTX là khách quan, } \\
\text { không làm phương hại đển hiệu quả của HTX. }\end{array}$ & 216 & 2 & 5 & 3,25 &, 595 \\
\hline DN4 & $\begin{array}{l}\text { Chế độ lương và đãi ngộ của HTX được công bố công } \\
\text { khai trong HTX. }\end{array}$ & 216 & 1 & 5 & 3,77 & 697 \\
\hline DN5 & $\begin{array}{l}\text { Chế độ lương và đãi ngộ của HTX là công bằng cho } \\
\text { tất cả nhân viên. }\end{array}$ & 216 & 1 & 5 & 3,35 & ,658 \\
\hline \multicolumn{7}{|c|}{ Thang đo: Hiệu quả tài chính } \\
\hline TC1 & Doanh thu của HTX ngày càng tăng. & 216 & 2 & 5 & 3,31 & ,519 \\
\hline TC2 & Lợi nhuận của HTX ngày càng tăng. & 216 & 2 & 5 & 3,31 & ,531 \\
\hline TC3 & Năng suất sản phẩm của HTX ngày càng tăng. & 216 & 1 & 5 & 3,32 & ,566 \\
\hline TC4 & Thị phần của HTX ngày càng tăng. & 216 & 2 & 5 & 3,31 &, 528 \\
\hline TC5 & $\begin{array}{l}\text { Về tổng quan, hiệu quả kinh doanh của HTX ngày } \\
\text { càng tăng. }\end{array}$ & 216 & 1 & 5 & 3,28 &, 584 \\
\hline \multicolumn{7}{|c|}{ Thang đo: Hiệu quả phi tài chính } \\
\hline PTC1 & $\begin{array}{l}\text { Chất lượng sản phẩm/dịch vụ của HTX ngày càng } \\
\text { tăng. }\end{array}$ & 216 & 2 & 5 & 3,61 &, 551 \\
\hline PTC2 & $\begin{array}{l}\text { Năng lực cạnh tranh về giá cả của HTX ngày càng } \\
\text { tăng. }\end{array}$ & 216 & 1 & 5 & 3,54 & ,646 \\
\hline PTC3 & $\begin{array}{l}\text { HTX có mức tiết kiệm chi phí sản phẩm ngày càng } \\
\text { cao. }\end{array}$ & 216 & 1 & 5 & 3,58 & 620 \\
\hline PTC4 & HTX phát triển được nhiều sản phẩm mới. & 216 & 1 & 5 & 3,56 & ,637 \\
\hline PTC5 & Sự hài lòng của khách hàng ngày càng cao. & 216 & 1 & 5 & 3,60 & ,570 \\
\hline PTC6 & HTX ngày càng quan tâm đến quyền sở hữu trí tuệ. & 216 & 2 & 5 & 3,60 &, 553 \\
\hline PTC7 & Uy tín của HTX ngày càng tăng. & 216 & 1 & 5 & 3,54 & ,653 \\
\hline PTC8 & Hình ảnh của HTX ngày càng mở rộng. & 216 & 2 & 5 & 3,60 &, 536 \\
\hline PTC9 & $\begin{array}{l}\text { Các dịch vụ phục vụ khách hàng của HTX ngày càng } \\
\text { tốt hơn. }\end{array}$ & 216 & 2 & 5 & 3,62 &, 550 \\
\hline
\end{tabular}

Nguồn: Kết quả phân tích dữ liệu của nhóm nghiên cứu

Kết quả thống kê mô tả (Bảng 2) cho thấy, ở thang đo tuyển dụng và lựa chọn lao động, các HTX đánh giá cao về việc HTX có xây dựng tiêu chí cụ thể về kỹ năng và năng lực cần 
thiết mà nhân viên mới phải có (thể hiện qua biến TD2 có giá trị trung bình là 3,75 ) và quá trình tuyển dụng nhân sự mới của HTX diễn ra công bằng (thể hiện qua biến TD4 có giá trị trung bình là 3,70$)$.

Ở thang đo đào tạo lao động, các HTX đánh giá cao về việc HTX có thường xuyên khảo sát về nhu cầu nâng cao trình độ của nhân viên (thể hiện qua biến DT1 có giá trị trung bình là $3,56)$.

Thang đo thị trường lao động nội bộ chưa được các HTX đánh giá cao, các quan sát có giá trị trung bình nhỏ hơn 3,50 (từ 3,05 đến 3,30), trong đó biến TT3 (nhân viên được tạo cơ hội bổ nhiệm vào vị trí điều hành HTX) được đánh giá cao nhất với giá trị trung bình là 3,30.

Thang đo sự tham gia của nhân viên, các HTX đánh giá khá cao việc Lãnh đạo HTX tạo điều kiện cho nhân viên đề xuất cải tiến hoạt động của HTX (biến TG3 có giá trị trung bình là 3,67 ) và Lãnh đạo HTX có yêu cầu các Trưởng bộ phận của HTX tham khảo ý kiến của nhân viên trong quá trình ra quyết định (biến TG2 có giá trị trung bình là 3,62).

Đối với thang đo chế độ lương và đãi ngộ, các HTX đánh giá khá cao biến DN1 (Chế độ lương và đãi ngộ của HTX phản ánh đúng tính chất công việc) và biến DN4 (Chế độ lương và đãi ngộ của HTX được công bố công khai trong HTX) cùng có giá trị trung bình là 3,77.

Thang đo hiệu quả tài chính chưa được các HTX đánh giá cao, các quan sát có giá trị trung bình nhỏ hơn 3,50 (từ 3,28 đến 3,32), trong đó biến TC3 (năng suất sản phẩm của HTX ngày càng tăng) được đánh giá cao nhất với giá trị trung bình là 3,32.

Thang đo hiệu quả phi tài chính được các HTX đánh giá khá cao (giá trị trung bình trong khoảng từ 3,54 đến 3,62), trong đó dịch vụ phục vụ khách hàng của HTX ngày càng tốt hơn (PT9) có giá trị trung bình cao nhất là 3,62 và kế đến là chất lượng sản phẩm/dịch vụ của $\mathrm{HTX}$ ngày càng tăng $(\mathrm{PTC} 1)$ với giá trị trung bình là 3,61.

\subsection{Kiểm định Cronbach's Alpha}

Kết quả phân tích Cronbach's Alpha được thể hiện trong Bảng 3 như sau:

\section{Bảng 3}

Kết quả kiểm định Cronbach’s Alpha

\begin{tabular}{|c|c|c|c|c|}
\hline Biến quan sát & $\begin{array}{c}\text { Trung bình } \\
\text { thang đo nếu } \\
\text { loại biến }\end{array}$ & $\begin{array}{c}\text { Phương sai } \\
\text { thang đo nếu } \\
\text { loại biến }\end{array}$ & $\begin{array}{c}\text { Hệ số tương } \\
\text { quan biến tổng }\end{array}$ & $\begin{array}{c}\text { Hệ số Cronbach's } \\
\text { Alpha nếu loại biến }\end{array}$ \\
\hline \multicolumn{5}{|c|}{ Hệ số Cronbach's Alpha thang đo "Tuyển dụng và lựa chọn lao động": 0,864 } \\
\hline TD1 & 17,24 & 7,774 & 698 & ,835 \\
\hline TD2 & 16,80 & 7,893 & 691 & 836 \\
\hline TD3 & 17,29 & 7,891 & 667 & 840 \\
\hline TD4 & 16,84 & 8,043 & 605 & ,851 \\
\hline TD5 & 17,39 & 7,886 & 633 & ,846 \\
\hline TD6 & 17,15 & 7,838 & 662 & 841 \\
\hline \multicolumn{5}{|c|}{ Hệ số Cronbach's Alpha thang đo "Đào tạo lao động": 0,860 } \\
\hline DT1 & 16,14 & 8,123 & ,620 & ,841 \\
\hline
\end{tabular}




\begin{tabular}{|c|c|c|c|c|}
\hline Biến quan sát & $\begin{array}{c}\text { Trung bình } \\
\text { thang đo nếu } \\
\text { loại biến }\end{array}$ & $\begin{array}{c}\text { Phương sai } \\
\text { thang đo nếu } \\
\text { loại biến }\end{array}$ & $\begin{array}{c}\text { Hệ số tương } \\
\text { quan biến tổng }\end{array}$ & $\begin{array}{l}\text { Hệ số Cronbach's } \\
\text { Alpha nếu loại biến }\end{array}$ \\
\hline DT2 & 16,49 & 7,777 & ,664 & ,833 \\
\hline DT3 & 16,26 & 7,637 & ,710 & 825 \\
\hline DT4 & 16,57 & 7,976 & ,690 & ,829 \\
\hline DT5 & 16,56 & 7,838 & ,609 & ,844 \\
\hline DT6 & 16,51 & 8,121 & 615 & ,842 \\
\hline \multicolumn{5}{|c|}{ Hệ số Cronbach's Alpha thang đo "Thị trường lao động nội bộ": 0,858} \\
\hline TT1 & 12,73 & 5,799 & ,693 & ,824 \\
\hline TT2 & 12,57 & 6,339 & 619 & ,842 \\
\hline TT3 & 12,52 & 6,139 & 627 & ,841 \\
\hline TT4 & 12,69 & 5,815 & ,735 & ,813 \\
\hline TT5 & 12,77 & 6,021 & ,699 & ,822 \\
\hline \multicolumn{5}{|c|}{ Hệ số Cronbach's Alpha thang đo "Sự tham gia của nhân viên": 0,829} \\
\hline TG1 & 16,70 & 5,300 & ,680 & ,784 \\
\hline TG2 & 16,22 & 5,709 & ,577 & ,806 \\
\hline TG3 & 16,18 & 5,001 & ,598 & ,805 \\
\hline TG4 & 16,61 & 5,635 & 608 & ,800 \\
\hline TG5 & 16,74 & 5,665 & 637 & ,796 \\
\hline TG6 & 16,77 & 5,255 & ,546 & ,815 \\
\hline \multicolumn{5}{|c|}{ Hệ số Cronbach's Alpha thang đo “Chế độ lương và đãi ngộ": 0,866 } \\
\hline DN1 & 13,64 & 4,165 & ,759 & ,819 \\
\hline DN2 & 14,13 & 4,424 & ,726 & ,830 \\
\hline DN3 & 14,17 & 4,301 & ,758 & ,821 \\
\hline DN4 & 13,65 & 4,257 & ,619 & ,858 \\
\hline DN5 & 14,07 & 4,428 & ,601 & ,860 \\
\hline \multicolumn{5}{|c|}{ Hệ số Cronbach's Alpha thang đo "Hiệu quả tài chính": 0,910 } \\
\hline TC1 & 13,22 & 3,659 & ,781 & ,888 \\
\hline TC2 & 13,21 & 3,589 & ,799 & ,884 \\
\hline TC3 & 13,20 & 3,521 & ,770 & 890 \\
\hline TC4 & 13,22 & 3,594 & ,803 & ,883 \\
\hline TC5 & 13,25 & 3,563 & ,714 & ,903 \\
\hline \multicolumn{5}{|c|}{ Hệ số Cronbach's Alpha thang đo "Hiệu quả phi tài chính": 0,925 } \\
\hline PTC1 & 28,64 & 13,981 & ,848 & ,910 \\
\hline PTC2 & 28,71 & 14,243 & ,640 & ,923 \\
\hline PTC3 & 28,67 & 14,064 & ,716 & ,917 \\
\hline PTC4 & 28,69 & 14,289 & ,640 & ,923 \\
\hline PTC5 & 28,65 & 14,108 & ,782 & ,913 \\
\hline PTC6 & 28,65 & 14,266 & ,768 & ,914 \\
\hline PTC7 & 28,71 & 14,328 & ,612 & ,925 \\
\hline PTC8 & 28,65 & 14,238 & ,804 & ,912 \\
\hline PTC9 & 28,63 & 14,094 & ,819 & ,911 \\
\hline
\end{tabular}

Nguồn: Tác giả thu thập dữ liệu và phân tích 
Các thang đo tuyển dụng và lựa chọn lao động, thang đo đào tạo lao động, thang đo thị trường lao động nội bộ, thang đo sự tham gia của nhân viên, thang đo chế độ lương và đãi ngộ nhân viên, thang đo hiệu quả tài chính, thang đo hiệu quả phi tài chính, đều có hệ số Cronbach's Alpha $>0,6$ và hệ số tương quan biến tổng của các biến quan sát đều $>0,3$ nên các biến này đều được đưa vào phân tích nhân tố tiếp theo. Như vậy, sau khi phân tích độ tin cậy của các thang đo qua hệ số Cronbach's Alpha, tổng cộng 42 biến trên gồm 28 biến thang đo các biến độc lập và 14 biến thang đo các biến phụ thuộc sẽ được đưa vào phân tích nhân tố EFA.

\subsection{Phân tích nhân tố khám phá (EFA)}

Kết quả phân tích EFA đối với các biến quan sát trong mô hình nghiên cứu được thể hiện trong Bảng 4, 5, 6, 7, 8, 9, 10 và 11 như sau:

\section{Bảng 4}

Kiểm định KMO và Barlett's đối với các thang đo biến độc lập

\begin{tabular}{|l|r|}
\hline \multicolumn{2}{|c|}{ Kiểm định KMO và Barlett's } \\
\hline Chỉ số KMO &, 839 \\
\hline Kiềm định Barlett's & 2979,666 \\
\hline df & 378 \\
\hline Sig. &, 000 \\
\hline
\end{tabular}

Nguồn: Kết quả xử lý từ dữ liệu điều tra

\section{Bảng 5}

Kết quả phân tích nhân tố EFA đối với các thang đo biến độc lập

\begin{tabular}{|c|c|c|c|c|c|c|}
\hline \multirow{2}{*}{ Mã hóa } & \multicolumn{5}{|c|}{ Nhân tố } \\
\hline & $\mathbf{1}$ & $\mathbf{2}$ & $\mathbf{3}$ & $\mathbf{4}$ & $\mathbf{5}$ & $\mathbf{6}$ \\
\hline DT3 &, 798 & & & & & \\
\hline DT2 &, 785 & & & & & \\
\hline DT4 &, 780 & & & & & \\
\hline DT5 &, 737 & & & & & \\
\hline DT1 &, 735 & & & & & \\
\hline DT6 &, 699 & & & & & \\
\hline TD1 & &, 804 & & & & \\
\hline TD6 & &, 783 & & & & \\
\hline TD3 & &, 778 & & & & \\
\hline TD5 & &, 762 & & & & \\
\hline TD2 & &, 758 & & & & \\
\hline TD4 & &, 701 & & & & \\
\hline TT4 & & &, 819 & & & \\
\hline TT1 & & &, 795 & & & \\
\hline TT5 & & &, 787 & & & \\
\hline TT3 & & &, 764 & & & \\
\hline TT2 & & &, 668 & & & \\
\hline DN3 & & & &, 856 & & \\
\hline DN2 & & & &, 833 & & \\
\hline DN1 & & & &, 831 & & \\
\hline
\end{tabular}




\begin{tabular}{|c|r|r|r|r|r|r|}
\hline \multirow{2}{*}{ Mã hóa } & \multicolumn{5}{|c|}{ Nhân tó́ } \\
\cline { 2 - 7 } & $\mathbf{1}$ & $\mathbf{2}$ & $\mathbf{3}$ & $\mathbf{4}$ & $\mathbf{5}$ & $\mathbf{6}$ \\
\hline DN5 & & & &, 744 & & \\
\hline DN4 & & & &, 726 & & \\
\hline TG1 & & & & &, 765 & \\
\hline TG4 & & & & &, 744 & \\
\hline TG5 & & & & &, 665 & \\
\hline TG6 & & & & & &, 753 \\
\hline TG3 & & & & & &, 682 \\
\hline TG2 & & & & & &, 549 \\
\hline Eigenvalues & 6,508 & 3,545 & 2,967 & 2,778 & 1,473 & 1,028 \\
\hline Phương sai trích (\%) & 13,028 & 26,022 & 38,501 & 50,605 & 58,664 & 65,566 \\
\hline
\end{tabular}

Nguồn: Kết quả xử lý từ dữ liệu điều tra

\section{Bảng 6}

Kiểm định $\mathrm{KMO}$ và Barlett's đối với thang đo hiệu quả tài chính

\begin{tabular}{|l|r|}
\hline \multicolumn{2}{|c|}{ Kiểm định KMO và Barlett's } \\
\hline Chỉ số KMO &, 889 \\
\hline Kiểm định Barlett's & 692,586 \\
\hline df & 10 \\
\hline Sig. &, 000 \\
\hline
\end{tabular}

Nguồn: Kết quả xử lý từ dữ liệu điều tra

\section{Bảng 7}

Kết quả phân tích nhân tố EFA đối với thang đo hiệu quả tài chính

\begin{tabular}{|c|l|r|}
\hline Mã hóa & \multicolumn{1}{|c|}{ Biến quan sát } & Hệ số tải nhân tố \\
\hline TC4 & Thị phần của HTX ngày càng tăng. &, 881 \\
\hline TC2 & Lợi nhuận của HTX ngày càng tăng. &, 880 \\
\hline TC1 & Doanh thu của HTX ngày càng tăng. &, 865 \\
\hline TC3 & Năng suất sản phẩm của HTX ngày càng tăng. \\
\hline TC5 & $\begin{array}{l}\text { Về tổng quan, hiệu quả kinh doanh của HTX ngày } \\
\text { càng tăng. }\end{array}$ &, 813 \\
\hline & Eigenvalues & 3,692 \\
\hline \multicolumn{2}{|c|}{ Phương sai trích (\%) } \\
\hline
\end{tabular}

Nguồn: Kết quả xử lý từ dữ liệu điều tra

\section{Bảng 8}

Kiểm định $\mathrm{KMO}$ và Barlett's đối với thang đo hiệu quả phi tài chính

\begin{tabular}{|l|r|}
\hline \multicolumn{2}{|c|}{ Kiểm định KMO và Barlett's } \\
\hline Chỉ số KMO &, 931 \\
\hline Kiểm định Barlett's & 1334,444 \\
\hline df & 36 \\
\hline Sig. &, 000 \\
\hline
\end{tabular}

Nguồn: Kết quả xử lý từ dữ liệu điều tra 


\section{Bảng 9}

Kết quả phân tích nhân tố EFA đối với thang đo hiệu quả phi tài chính

\begin{tabular}{|c|l|r|}
\hline Mã hóa & \multicolumn{1}{|c|}{ Biến quan sát } & \multicolumn{1}{c|}{ Hệ số tải nhân tố } \\
\hline PTC1 & Chất lượng sản phẩm/dịch vụ của HTX ngày càng tăng. &, 892 \\
\hline PTC9 & Các dịch vụ phục vụ khách hàng của HTX ngày càng tăng. &, 867 \\
\hline PTC8 & Hình ảnh của HTX ngày càng tăng. &, 861 \\
\hline PTC5 & Sự hài lòng của khách hàng ngày càng cao. &, 845 \\
\hline PTC6 & HTX ngày càng quan tâm đến quyền sở hữu trí tuệ. &, 827 \\
\hline PTC3 & HTX có mức tiết kiệm chi phí sản phẩm ngày càng cao. &, 783 \\
\hline PTC4 & HTX phát triển được nhiều sản phẩm mới. &, 706 \\
\hline PTC2 & Năng lực cạnh tranh về giá cả của HTX ngày càng tăng. &, 683 \\
\hline PTC7 & Uy tín của HTX ngày càng tăng. & 5,774 \\
\hline & Eigenvalues & 64,159 \\
\hline
\end{tabular}

Nguồn: Kết quả xử lý từ dữ liệu điều tra

Đối với thang đo các biến độc lập: 28 biến quan sát của các thang đo thực tiễn QTNNL sau khi kiểm tra độ tin cậy thông qua hệ số Cronbach's Alpha đạt, được đưa vào phân tích nhân tố khám phá EFA. Qua kết quả phân tích nhân tố khám phá EFA, hệ số KMO và kiểm định Barlett's khá cao 0,839 và thỏa mãn yêu cầu $0,5 \leq \mathrm{KMO} \leq 1$, có ý nghĩa thống kê $(\mathrm{Sig} .=0,000)$ cho thấy các biến quan sát có tương quan với nhau xét trên phạm vi tổng thể và phân tích nhân tố EFA là thích hợp. Mức Eigenvalue $>1$ ta có 6 nhân tố được rút ra từ 28 biến quan sát với phương sai trích $65,566 \%$ lớn hơn $50 \%$ cho thấy $65,566 \%$ biến thiên của dữ liệu được giải thích bởi 28 nhân tố này. Tất cả hệ số tải nhân tố của các biến quan sát của các thang đo biến độc lập đều $>0,3$.

Qua kết quả phân tích nhân tố khám phá EFA, hệ số KMO và kiểm định Barlett's khá cao 0,889 và thỏa mãn yêu cầu $0,5 \leq \mathrm{KMO} \leq 1$, có ý nghĩa thống kê ( $\operatorname{Sig}=0.000$ ) cho thấy các biến quan sát có tương quan với nhau xét trên phạm vi tổng thể và phân tích nhân tố EFA là thích hợp. Mức Eigenvalue $>1$ ta có 1 nhân tố được rút ra từ 5 biến quan sát với phương sai trích $73,835 \%$ lớn hơn $50 \%$. Tất cả hệ số tải nhân tố của các biến quan sát của các thang đo biến độc lập đều $>0,3$.

Sau khi phân tích nhân tố EFA, từ 28 biến quan sát hội tụ thành 6 nhân tố (Bảng 5):

Nhân tố thứ 1: gồm 6 biến quan sát đều ở thành phần đào tạo lao động nên ta đặt tên nhân tố này là Đào tạo lao động (DT).

Nhân tố thứ 2: gồm 6 biến quan sát đều ở thành phần tuyển dụng và lựa chọn lao động nên ta đặt tên nhân tố này là Tuyển dụng và lựa chọn lao động (TD).

Nhân tố thứ 3: gồm 5 biến quan sát đều ở thành phần chế độ lương và đãi ngộ nên ta đặt tên nhân tố này là Chế độ lương và đãi ngộ $(D N)$. 
Nhân tố thứ 4: gồm 5 biến quan sát đều ở thành phần thị trường lao động nội bộ nên ta đặt tên nhân tố này là Thị trương lao động nội bộ (TT).

Nhân tố thứ 5 : gồm 3 biến quan sát được tách ra từ thành phần sự tham gia của nhân viên và được đặt tên mới là Giao tiếp giũa lãnh đạo và nhân viên (GTIEP).

Đối với thang đo biến phụ thuộc hiệu quả tài chính: 5 biến quan sát của các thang đo hiệu quả tài chính sau khi kiểm tra độ tin cậy thông qua hệ số Cronbach's Alpha đạt, được đưa vào phân tích nhân tố khám phá EFA. Qua kết quả phân tích nhân tố khám phá EFA, hệ số $\mathrm{KMO}$ và kiểm định Barlett's khá cao 0,889 và thỏa mãn yêu cầu $0,5 \leq \mathrm{KMO} \leq 1$, có ý nghĩa thống kê $(\mathrm{Sig}=0.000)$ cho thấy các biến quan sát có tương quan với nhau xét trên phạm vi tổng thể và phân tích nhân tố EFA là thích hợp. Mức Eigenvalue $>1$ ta có 1 nhân tố được rút ra từ 5 biến quan sát với phương sai trích 73,835\% lớn hơn $50 \%$. Tất cả hệ số tải nhân tố của các biến quan sát của thang đo biến hiệu quả tài chính đều $>0,3$.

Đối với thang đo biến phụ thuộc hiệu quả phi tài chính: 9 biến quan sát của các thang đo hiệu quả phi tài chính sau khi kiểm tra độ tin cậy thông qua hệ số Cronbach's Alpha đạt, được đưa vào phân tích nhân tố khám phá EFA. Qua kết quả phân tích nhân tố khám phá EFA, hệ số $\mathrm{KMO}$ và kiểm định Barlett's cao 0,931 và thỏa mãn yêu cầu $0,5 \leq \mathrm{KMO} \leq 1$, có ý nghĩa thống kê $(\mathrm{Sig}=0.000)$ cho thấy các biến quan sát có tương quan với nhau xét trên phạm vi tổng thể và phân tích nhân tố EFA là thích hợp. Mức Eigenvalue $>1$ ta có 1 nhân tố được rút ra từ 9 biến quan sát với phương sai trích $64,159 \%$ lớn hơn $50 \%$. Tất cả hệ số tải nhân tố của các biến quan sát của thang đo biến hiệu quả phi tài chính đều $>0,3$.

\subsection{Phân tích hồi quy đa biến}

Mô hình hồi quy 1 tiến hành phân tích hồi quy tuyến tính bội giữa các biến độc lập với biến phụ thuộc Hiệu quả tài chính (TC) như sau:

$$
\mathrm{TC}=\beta_{0}+\beta_{1} \mathrm{TD}+\beta_{2} \mathrm{DT}+\beta_{3} \mathrm{TT}+\beta_{4} \mathrm{DN}+\beta_{5} \mathrm{TG}+\beta_{6} \mathrm{GTIEP}
$$

\section{Bảng 10}

Phân tích ANOVA mô hình hồi quy 1

\begin{tabular}{|c|c|c|c|c|c|c|c|}
\hline \multicolumn{8}{|c|}{ Bảng tóm tắt mô hình hồi quy 1} \\
\hline Mô hình & $\mathrm{R}$ & $\mathrm{R}^{2}$ & \multicolumn{2}{|c|}{$\mathrm{R}^{2}$ điều chỉnh } & $\begin{array}{c}\text { Sai số chuẩn ước } \\
\text { tính }\end{array}$ & \multicolumn{2}{|c|}{$\begin{array}{l}\text { Hệ số Durbin- } \\
\text { Watson }\end{array}$} \\
\hline 1 & ,805 & ,648 & \multicolumn{2}{|l|}{,638 } & 28173 & \multicolumn{2}{|c|}{2,208} \\
\hline \multicolumn{8}{|c|}{ Bảng ANOVA } \\
\hline Mô hình & & & $\begin{array}{l}\text { Tồng các bình } \\
\text { phương }\end{array}$ & df & $\begin{array}{l}\text { Bình phương } \\
\text { trung bình }\end{array}$ & $\mathrm{F}$ & Sig. \\
\hline \multirow{3}{*}{1} & \multicolumn{2}{|c|}{ Phần hồi quy } & 30,526 & 6 & 5,088 & 64,099 &, 000 \\
\hline & \multicolumn{2}{|c|}{ Phần dư } & 16,589 & 209 & ,079 & & \\
\hline & \multicolumn{2}{|c|}{ Phần tổng } & 47,115 & 215 & & & \\
\hline Biến phụ & luộc: T & & & & & & \\
\hline
\end{tabular}

Nguồn: Kết quả xử lý từ dữ liệu điều tra 


\section{Bảng 11}

Hệ số hồi quy mô hình 1

\begin{tabular}{|c|c|c|c|c|c|c|c|c|}
\hline \multirow{2}{*}{$\begin{array}{l}\text { Mồ } \\
\text { hình }\end{array}$} & \multirow[t]{2}{*}{ Biến } & \multicolumn{2}{|c|}{$\begin{array}{c}\text { Hệ số hồi quy chưa } \\
\text { chuẩn hóa }\end{array}$} & \multirow{2}{*}{$\begin{array}{c}\begin{array}{c}\text { Hệ số hồi } \\
\text { quy đã } \\
\text { chuẩn hóa }\end{array} \\
\beta\end{array}$} & \multirow{2}{*}{$\mathbf{t}$} & \multirow{2}{*}{ Sig. } & \multicolumn{2}{|c|}{$\begin{array}{c}\text { Thống kê đa cộng } \\
\text { tuyến }\end{array}$} \\
\hline & & B & $\begin{array}{l}\text { Sai số } \\
\text { chuẩn }\end{array}$ & & & & $\begin{array}{l}\text { Độ chấp } \\
\text { nhận }\end{array}$ & VIF \\
\hline \multirow{7}{*}{1} & Hằng số &,- 526 & ,203 & & $-2,592$ & ,010 & & \\
\hline & TD & ,230** & ,036 &, 272 & 6,449 & ,000 & ,946 & 1,057 \\
\hline & DT & ,240** & , 037 & ,284 & 6,541 & ,000 & ,892 & 1,122 \\
\hline & TT &, $198 * *$ & ,039 & ,255 & 5,115 &, 000 & ,678 & 1,474 \\
\hline & $\mathrm{DN}$ & ,193** & ,040 & 211 & 4,891 & ,000 & ,905 & 1,104 \\
\hline & TG & ,189** &, 052 & , 198 & 3,643 & ,000 &, 573 & 1,746 \\
\hline & GTIEP & ,104* &, 045 &, 121 & 2,279 &, 024 & ,601 & 1,665 \\
\hline
\end{tabular}

Ghi chú: ** là ý nghĩa ở mức $1 \%$,* là mức ý nghĩa $5 \%$

Nguồn: Kết quả xử lý từ dữ liệu điều tra

Mô hình hồi quy 2 tiến hành phân tích hồi quy tuyến tính bội giữa các biến độc lập với biến phụ thuộc Hiệu quả phi tài chính (PTC) như sau:

$$
\mathrm{PTC}=\beta_{0}+\beta_{1} \mathrm{TD}+\beta_{2} \mathrm{DT}+\beta_{3} \mathrm{TT}+\beta_{4} \mathrm{DN}+\beta_{5} \mathrm{TG}+\beta_{6} \mathrm{GTIEP}
$$

\section{Bảng 12}

Phân tích ANOVA mô hình hồi quy 2

\begin{tabular}{|c|c|c|c|c|c|c|c|}
\hline \multicolumn{8}{|c|}{ Bảng tóm tắt mô hình hồi quy 2} \\
\hline $\begin{array}{l}\text { Mồ } \\
\text { hình }\end{array}$ & $\mathrm{R}$ & $\mathrm{R}^{2}$ & \multicolumn{2}{|c|}{$\mathrm{R}^{2}$ điều chỉnh } & $\begin{array}{c}\text { Sai số chuẩn ước } \\
\text { tính }\end{array}$ & \multicolumn{2}{|c|}{ Hệ số Durbin-Watson } \\
\hline 1 & ,781 &, 610 & \multicolumn{2}{|c|}{,599 } & 29674 & \multicolumn{2}{|r|}{1,910} \\
\hline \multicolumn{8}{|c|}{ Bảng ANOVA } \\
\hline $\begin{array}{l}\text { Mô } \\
\text { hình }\end{array}$ & & \multicolumn{2}{|c|}{$\begin{array}{l}\text { Tổng các bình } \\
\text { phương }\end{array}$} & df & $\begin{array}{c}\text { Bình } \\
\text { phương } \\
\text { trung bình }\end{array}$ & $\mathrm{F}$ & Sig. \\
\hline \multirow{3}{*}{1} & \multicolumn{2}{|c|}{ Phần hồi quy } & 28,787 & 6 & 4,798 & 54,486 & ,000 \\
\hline & \multicolumn{2}{|l|}{ Phần dư } & 18,404 & 209 &, 088 & & \\
\hline & \multicolumn{2}{|l|}{ Phần tổng } & 47,191 & 215 & & & \\
\hline
\end{tabular}

Nguồn: Kết quả xử lý từ dữ liệu điều tra 


\section{Bảng 13}

Hệ số hồi quy mô hình 2

\begin{tabular}{|c|c|c|c|c|c|c|c|c|}
\hline \multirow[t]{2}{*}{$\begin{array}{l}\text { Mô } \\
\text { hình }\end{array}$} & \multirow[t]{2}{*}{ Biến } & \multicolumn{2}{|c|}{$\begin{array}{c}\text { Hệ số hồi quy chưa } \\
\text { chuẩn hóa }\end{array}$} & \multirow{2}{*}{ 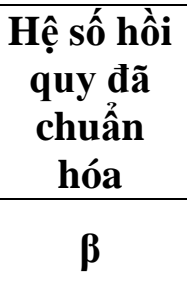 } & \multirow[t]{2}{*}{$\mathbf{t}$} & \multirow{2}{*}{ Sig. } & \multicolumn{2}{|c|}{$\begin{array}{c}\text { Thống kê đa cộng } \\
\text { tuyến }\end{array}$} \\
\hline & & B & $\begin{array}{l}\text { Sai số } \\
\text { chuâ̂n }\end{array}$ & & & & $\begin{array}{c}\text { Độ chấp } \\
\text { nhận }\end{array}$ & VIF \\
\hline \multirow{7}{*}{1} & Hằng số & 341 & ,206 & & 1,652 &, 100 & & \\
\hline & TD & $311 * *$ & 038 & 368 & 8,294 & 000 & 946 & 1,057 \\
\hline & DT & $167 * *$ &, 039 &, 198 & 4,333 &, 000 &, 892 & 1,122 \\
\hline & TT &, $309 * *$ & ,041 & ,398 & 7,587 & ,000 & ,678 & 1,474 \\
\hline & DN &, $189 * *$ &, 042 & 206 & 4,538 &, 000 & ,905 & 1,104 \\
\hline & $\mathrm{TG}$ &,- 055 & 055 &,- 058 & $-1,013$ & 312 & .573 & 1,746 \\
\hline & GTIEP & $150 * *$ & ,048 & 174 & 3,130 & 002 & ,601 & 1,665 \\
\hline
\end{tabular}

Ghi chú: ** là ý nghĩa ở mức $1 \%$

Nguồn: Kết quả xử lý từ dữ liệu điều tra

Kết quả hồi quy cho thấy các giả thuyết được kiểm định như sau:

\begin{tabular}{|l|l|c|}
\hline Giả thuyết & \multicolumn{1}{|c|}{$\begin{array}{c}\text { Kết quả kiểm } \\
\text { định }\end{array}$} \\
\hline H1.a & $\begin{array}{l}\text { Tuyển dụng và lựa chọn lao động càng hiệu quả thì hiệu quả tài chính } \\
\text { càng cao. }\end{array}$ & Chấp nhận \\
\hline H1.b & $\begin{array}{l}\text { Tuyền dụng và lựa chọn lao động càng hiệu quả thì hiệu quả phi tài chính } \\
\text { càng cao. }\end{array}$ & Chấp nhận \\
\hline H2.a & Đào tạo lao động càng được đầu tư nhiều thì hiệu quả tài chính càng cao. & Chấp nhận \\
\hline H2.b & $\begin{array}{l}\text { Đào tạo lao động càng được đầu tư nhiều thì hiệu quả phi tài chính càng } \\
\text { cao. }\end{array}$ & Chấp nhận \\
\hline H3.a & $\begin{array}{l}\text { Nhân viên được trao cơ hội thăng tiến thông qua thị trường lao động nội } \\
\text { bộ càng nhiều thì hiệu quả tài chính càng cao. }\end{array}$ & Chấp nhận \\
\hline H3.b & $\begin{array}{l}\text { Nhân viên được trao cơ hội thăng tiến thông qua thị trường lao động nội } \\
\text { bộ càng nhiều thì hiệu quả phi tài chính càng cao. }\end{array}$ & Chấp nhận \\
\hline H4.a & $\begin{array}{l}\text { Chế độ lương và đãi ngộ cho nhân viên càng nhiều thì hiệu quả tài chính } \\
\text { càng cao. }\end{array}$ & Chấp nhận \\
\hline H4.b & $\begin{array}{l}\text { Chế độ lương và đãi ngộ cho nhân viên càng nhiều thì hiệu quả phi tài } \\
\text { chính càng cao. }\end{array}$ & Chấp nhận \\
\hline H5.a & Sự tham gia của nhân viên càng nhiều thì hiệu quả tài chính càng cao. & Chấp nhận \\
\hline H5.b & $\begin{array}{l}\text { Sự tham gia của nhân viên càng nhiều thì hiệu quả phi tài chính càng } \\
\text { cao. }\end{array}$ & Loại bỏ \\
\hline H6.a & $\begin{array}{l}\text { Giao tiếp giữa lãnh đạo với nhân viên càng nhiều thì hiệu quả phi tài } \\
\text { chính càng cao. }\end{array}$ & Chấp nhận \\
\hline H6.b & $\begin{array}{l}\text { Giao tiếp giữa lãnh đạo với nhân viên càng nhiều thì hiệu quả phi tài } \\
\text { chính càng cao. }\end{array}$ & Chấp nhận \\
\hline
\end{tabular}

Nguồn: Kết quả xử lý từ dữ liệu điều tra 


\subsection{Thảo luận kết quả nghiên cứu}

Yếu tố tuyển dụng và lựa chọn lao động tác động tích cực đến 2 yếu tố hiệu quả tài chính $(\beta=0,272, p<0,01)$, hiệu quả phi tài chính $(\beta=0,368, p<0,01)$. Kết quả này tương đồng với kết quả nghiên cứu Delaney và Huselid (1996), Harel và Tzfrir (1999), Moideenkutty, AlLamki, và Murthy (2011), Rhee et al. (2014). Điều này phù hợp với thực tế tại các HTX, nếu tiến hành tuyển dụng và lựa chọn lao động càng hiệu quả thì HTX sẽ lựa chọn được những nhân viên có tố chất phù hợp với công việc và từ đó mang lại hiệu quả cho HTX. Qua khảo sát, các HTX đánh giá cao việc HTX nên có xây dựng tiêu chí cụ thể trong tuyển dụng và lựa chọn nhân viên và được tiến hành một cách công bằng. Tuy nhiên, các HTX cần xây dựng nhiều chương trình tuyển dụng khác nhau và nên có sự tham gia của các cán bộ chủ chốt để thu hút những nhân viên có năng lực về làm việc tại HTX.

Yếu tố đào tạo lao động là yếu tố tác động mạnh nhất đến hiệu quả tài chính và ( $\beta=$ $0,284, \mathrm{p}<0,01)$ và cũng có tác động đến hiệu quả phi tài chính $(\beta=0,198, \mathrm{p}<0,01)$. Kết quả này tương đồng với kết quả nghiên cứu của Delaney và Huselid (1996), Harel và Tzfrir (1999), Moideenkutty et al. (2011), Rhee và cộng sự (2014). Việc đầu tư tốt cho công tác đào tạo sẽ giúp các HTX có được đội ngũ nhân viên giỏi, lành nghề, mang lại hiệu quả cao cho tổ chức. Hiện tại, các HTX đã thường xuyên khảo sát về nhu cầu nâng cao trình độ của nhân viên để đạt hiệu quả công tác đào tạo nhưng lại chưa quan tâm nhiều đến việc đánh giá kết quả học tập của nhân viên sau khi hoàn thành chương trình.

Yếu tố thị trương lao động nội bộ là yếu tố tác động mạnh thứ ba (sau đào tạo, tuyển dụng và lựa chọn) đến hiệu quả tài chính và $(\beta=0,255, \mathrm{p}<0,01)$ và là yếu tố tác động mạnh nhất đến hiệu quả phi tài chính $(\beta=0,398, \mathrm{p}<0,01)$. Kết quả này tương đồng với kết quả nghiên cứu của Delaney và Huselid (1996), Harel và Tzfrir (1999). Khi nhân viên được HTX trao cơ hội thăng tiến thông qua thị trường lao động nội bộ càng nhiều thì họ sẽ có thêm động lực làm việc, cống hiến nhiều hơn cho HTX, giúp tổ chức đạt được hiệu quả cao. Tuy nhiên, công tác quy hoạch nhân sự cũng như luân chuyển, tạo điều kiện cho nhân viên phát triển ở nhiều vị trí khác nhau chưa được HTX quan tâm đúng mức và chưa được đánh giá cao.

Yếu tố chế độ lvơng và đãi ngộ tác động tích cực đến 2 yếu tố hiệu quả tài chính ( $\beta=$ $0,211, \mathrm{p}<0,01)$, hiệu quả phi tài chính $(\beta=0,206, \mathrm{p}<0,01)$. Kết quả này tương đồng với kết quả nghiên cứu Harel và Tzfrir (1999), Rhee và cộng sự (2014). Chế độ lương và đãi ngộ là yếu tố giúp nhân viên gắn bó lâu dài, là động lực giúp họ làm việc hiệu quả hơn và đóng góp chung vào hiệu quả của HTX. Vì vậy, các HTX cần xây dựng chế độ lương và đãi ngộ khách quan, đảm bảo công bằng cho tất cả nhân viên và có thông tin công khai trong nội bộ HTX.

Yếu tố sư tham gia của nhân viên chỉ có tác động tích cực đến hiệu quả tài chính ( $\beta=$ $0,198, \mathrm{p}<0,01)$ và không có tác động đến hiệu quả phi tài chính. Kết quả này có sự khác biệt với kết quả nghiên cứu của Harel và Tzfrir (1999), Rhee và cộng sự (2014). Khi nhân viên được tạo điều kiện tham gia vào hoạt động cũng như các quyết định, kế hoạch của HTX càng nhiều thì họ có thêm động lực để nghiên cứu, đề xuất các giải pháp, sáng kiến cho tổ chức.

Yếu tố giao tiếp giũa lãnh đạo và nhân viên tác động tích cực đến 2 yếu tố hiệu quả tài chính $(\beta=0,121, \mathrm{p}<0,05)$, hiệu quả phi tài chính $(\beta=0,174, \mathrm{p}<0,01)$. Việc lãnh đạo và nhân 
viên có sự giao tiếp thông suốt sẽ giúp các bên hiểu nhau hơn và giúp việc ra quyết định của lãnh đạo HTX có độ chính xác và khách quan hơn.

\section{Kết luận và khuyến nghị}

\subsection{Kết luận}

Nghiên cứu các thành phần của thực tiễn QTNNL ảnh hưởng đến hiệu quả của HTX trên địa bàn TP.HCM với các thành phần như tuyển dụng và lựa chọn lao động, đào tạo lao động, thị trường lao động nội bộ, sự tham gia của nhân viên và chế độ lương và đãi ngộ nhân viên. Nghiên cứu được thực hiện thông qua 2 bước: nghiên cứu định tính và nghiên cứu định lượng. Nghiên cứu định tính được thực hiện bằng việc phỏng vấn sâu 10 người là lãnh đạo của các HTX trên địa bàn TP.HCM. Nghiên cứu định lượng được thực hiện với cỡ mẫu là $n=216$. Mô hình nghiên cứu và giả thuyết nghiên cứu được kiểm định thông qua phương pháp thống kê mô tả mẫu, phân tích độ tin cậy thang đo Cronbach's Alpha, phân tích nhân tố khám phá EFA, phân tích hồi quy đa biến. Nghiên cứu được thực hiện với 42 biến quan sát của 7 khái niệm trong mô hình. Kết quả phân tích hồi quy cho thấy 5 thành phần thực tiễn quản trị nguồn nhân lực (Tuyển dụng và lựa chọn lao động, đào tạo lao động, thị trường lao động nội bộ, sự tham gia của nhân viên và chế độ lương và đãi ngộ nhân viên) đều có tác động cùng chiều đến hiệu quả tài chính và hiệu quả phi tài chính của các hợp tác xã.

\subsection{Khuyến nghị}

\section{Đối với các HTX}

Để nâng cao hiệu quả tổ chức (hiệu quả tài chính và hiệu quả phi tài chính), các HTX cần xây dựng các giải pháp nhằm nâng cao các yếu tố về thực tiễn QTNNL như sau:

Đối với yếu tố tuyển dụng và lựa chọn lao động: HTX nên thực hiện những chương trình tuyển dụng khác nhau để thu hút nhiều hơn những nhân viên có năng lực, có thể tổ chức chương trình tuyển dụng từ các trường đại học, cao đẳng, trung cấp hoặc các trung tâm giới thiệu việc làm hay tuyển dụng trực tiếp từ việc phỏng vấn tại HTX. HTX cần xây dựng tiêu chí cụ thể về kỹ năng và năng lực cần thiết, đặc biệt là trình độ chuyên môn mà nhân viên mới phải có.

Đối với yếu tố đào tạo lao động: Các HTX hiện nay chưa quan tâm nhiều đến việc đào tạo theo nhu cầu của nhân viên và có đánh giá kết quả đào tạo sau khi nhân viên hoàn thành khóa học. Để các khóa đào tạo nhân viên đạt chất lượng cao, các HTX cần xây dựng nội dung đào tạo cụ thể, tập trung vào các kiến thức và kỹ năng thật sự cần thiết phù hợp với nhiều đối tượng nhân viên trong HTX (nhân viên kinh doanh, nhân viên kỹ thuật, nhân viên hành chínhkế toán,...) đáp ứng yêu cầu khách hàng, thị trường.

Đối với yếu tố thị trường lao động nội bộ: Lãnh đạo HTX nên có chính sách ưu tiên sử dụng nguồn nhân lực tại chỗ và nhận thức rằng các nhân viên hiện đang làm việc là nguồn dự bị sẵn sàng lấp đầy khoảng trống vị trí khi có nhân viên nghỉ việc trước khi nghĩ đến tìm kiếm các ứng viên bên ngoài HTX. Với bối cảnh hiện nay, Lãnh đạo HTX cần có quy hoạch các nhân viên có năng lực, tâm huyết, có thể gắn bó lâu dài với tổ chức để trở thành đội ngũ kế thừa hoặc được bổ nhiệm vào vị trí điều hành. Đối với yếu tố chế độ luơng và đãi ngộ cho nhân viên: Xây dựng chế độ lương và đãi ngộ nhân viên theo tính chất và yêu cầu công việc của mỗi nhân viên. HTX phải xây dựng hệ thống tiêu chuẩn hợp lý để phân chia bậc đối với các cán bộ. Các HTX 
cũng cần nghiên cứu xây dựng chế độ lương và đãi ngộ nhân viên dựa trên đánh giá công việc, phân tích công việc của từng nhân viên để đảm bảo sự công bằng cho tất cả nhân viên.

Đối với yếu tố sự tham gia của nhân viên: HTX cần xây dựng quy chế trưng cầu các ý kiến của nhân viên thông qua các buổi họp các phòng, ban, tổ sản xuất hoặc cho lập thùng thư góp ý trong khu vực hoạt động HTX. Lãnh đạo HTX nên cho phép và khuyến khích nhân viên bày tỏ ý kiến của mình và ghi nhận tất cả nguyện vọng của nhân viên. Mặt khác, Lãnh đạo HTX cũng quan tâm đến môi trường làm việc của nhân viên để có hướng hổ trợ cho nhân viên cải thiện môi trường làm việc tốt hơn.

Đối với yếu tố giao tiếp giũa lãnh đạo và nhân viên: Để khuyến khích nhân viên tham gia vào hoạt động của $\mathrm{HTX}$, cần tăng cường giao tiếp giữa lãnh đạo $\mathrm{HTX}$ và nhân viên.

\section{Đối với cơ quan quản lý nhà nước về HTX}

Cơ quan quản lý Nhà nước là phải hỗ trợ HTX trong việc đào tạo, bồi dưỡng nguồn nhân lực cho HTX. Điều này hoàn toàn phù hợp tình hình thực tế hiện nay khi các HTX còn hạn chế về tài chính, khó có thể quan tâm nhiều đến đào tạo lao động có chất lượng đáp ứng yêu cầu của thị trường và khách hàng.

Tạo môi trường thuận lợi để các HTX hoạt động và phát triển. suôn sẻ.

Tạo cầu nối giữa HTX - DN - người lao động - khách hàng để hoạt động của HTX được

\section{Tài liệu tham khảo}

Aref, F. (2011). Agricultural cooperatives for agricultural development in Iran. Life Science Journal, 8(1), 82-85.

Armstrong, M. (2006). A handbook of human resource management practice. London, UK: Kogan Page.

Armstrong, M., \& Taylor, S. (2014). Armstrong's handbook of human resource management practice. London, UK: Kogan Page.

Bartel, A. P. (1994). Productivity gains from the implementation of employee training programmes. Industrial Relations: A Journal of Economy and Society, 33 (4), 411-425.

Batt, R. (2002). Managing customer services: Human resource practices, quit rates, and sales growth. Academy of Management Journal, 45(3), 587-597.

Becker, B., \& Gerhart, B. (1996). The impact of human resource management on organizational performance: Progress and prospects. Academy of Management Journal, 39(4), 779-801.

Bratton, J., \& Gold, J. (2001). Human resource management: Theory and practice. New Jersey, USA: Lawrence Erlbaum.

Cappelli, P., \& Neumark, D. (2001). Do "high-performance" work practices improve establishment-level outcomes? Industrial \& Labor Relations Review, 54(4), 737-775. 
Combs, J., Liu, Y., Hall, A., \& Ketchen, D. (2006). How much do high-performance work practices matter? A meta-analysis of their effects on organizational performance. Personnel Psychology, 59(3), 501-528.

Delaney, J. T., \& Huselid, M. A. (1996). The impact of human resource management practices on perceptions of organizational performance. Academy of Management Journal, 39 (4), 949-969.

Doeringer, P. B., \& Piore, M. J. (1985). Internal labour markets and manpower analysis (2nd ed.). Armonk, NY: ME Sharpe.

Ekwoaba, J. O., Ikeije, U. U., \& Ufoma, N. (2015). The impact of recruitment and selection criteria on organizational performance. Global Journal of Human Resource Management, 3(2), 22-33.

Harel, G. H., \& Tzafrir, S. S. (1999). The effect of human resource management practices on the perceptions of organizational and market performance of the firm. Human Resource Management, 38(3), 185-199.

Huang, T. C. (2001). The relation of training practices and organizational performance in small and medium size enterprises. Education and Training, 43(8/9), 437-444.

Le, A. K. (2013). Impact of human resource management practices on organizational performance in small and medium enterprises in Thai Nguyen City (Doctoral dissertation, Southern Luzon State University, Republic of Philippines, Lucban, Quezon). Retrieved October, 20, 2018, from https://123doc.net/document/2240349-impact-of-humanresource-management-practices-on-the-organizational-performance-of-the-small-andmedium-enterprises-in-thai-nguyen-province.htm

Li, S., Ragu-Nathan, B., Ragu-Nathan, T. S., \& Rao, S. S. (2006). The impact of supply chain management practices on competitive advantage and organizational performance. Omega, 34(2), 107-124.

Quốc Hội. (2012). Luật Hợp tác xã, số 23/2012/QH13 của Quốc hội Nước Cộng hòa Xã họi Chủ nghĩa Việt Nam [Cooperative Law, No. 23/2012 / QH13 of the National Assembly of the Socialist Republic of Vietnam]. Retrieved October, 22, 2018, from https://thuvienphapluat.vn/van-ban/doanh-nghiep/Luat-hop-tac-xa-2012-23-2012QH13-152716.aspx

Makovskay, N. (2008). The internal labour market and development of human capital. Economics and Organization, 5(2), 151-160.

Mansour, M. (2010). HR practices impact on firm performance: An empirical study. King Fahd University of Petroleum and Minerals, 1(3), 6-34.

Marchington, M., Wilkinson, A., Ackers, P., \& Dundon, T. (2001). Management choice and employee voice. London, UK: CIPD.

Mathis, R. L., \& Jackson, J. H. (2010). Human resource management. Bunbury, Australia: South-Western College Pub. 
Moideenkutty, U., Al-Lamki, A., \& Murthy, Y. S. R. (2011). HRM practices and organizational performance in Oman. Personnel Review, 40(2), 239-251.

Morrison, E. W. (1996). Organizational citizenship behavior as a critical link between HRM practices and service quality. Human Resource Management, 35(4), 493-512.

Mutua, S. M., Karanja, K., \& Namusonge, G. S. (2012). Role of human resource management practices on performance of financial cooperatives based in Nairobi County, Kenya. International Journal of Humanities and Social Science, 2(22), 289-299.

Ofori, D., \& Aryeetey, M. (2011). Recruitment and selection practices in small and medium enterprises: Perspectives from Ghana. International Journal of Business Administration, 2(3), 45-60.

Price, A. (2007). Human resource management in a business context. Boston, MA: Cengage Learning EMEA.

Rhee, J. H., Zhao, X. F., \& Kim, C. H. (2014). Effects of HRM practices on Chinese firms' organizational performance: The moderating effect of CEO support. Asian Social Science, 10(13), 210-221.

Rogers, E. W., \& Wright, P. M. (1998). Measuring organizational performance in strategic human resource management: Problems, prospects and performance information markets. Human Resource Management Review, 8(3), 311-331.

Singh, K. (2004). Impact of HR practices on perceived firm performance in India. Asia Pacific Journal of Human Resources, 42(3), 301-317.

Strauss, G. (2006). Worker participation-some under-considered issues. Industrial Relations: A Journal of Economy and Society, 45(4), 778-803.

Terpstra, D. E., \& Rozell, E. J. (1993). The relationship of staffing practices to organizational level measures of performance. Personnel Psychology, 46(1), 27-48.

United Nations. (2003). Cooperatives provide vital health, housing, banking services, secretary-general speech for international day of cooperatives. Retrieved October, 28, 2018, from http://www.un.org/press/en/2003/sgsm8762.doc.htm

Valentinov, V. (2007). Why are cooperatives important in agriculture? An organizational economics perspective. Journal of Institutional Economics, 3(1), 55-69.

Wolz, A., \& Pham, D. B. (2010). The transformation of agricultural producer cooperatives: The case of Vietnam. Journal of Rural Cooperation, 38(2), 117-133.

Wright, P. M., McMahan, G. C., \& McWilliams, A. (1994). Human resources and sustained competitive advantage: A resource-based perspective. International Journal of Human Resource Management, 5(2), 301-326. 